\title{
Analysis of Lateral Dynamic Response of Caisson Foundation in Layered Clayey Soils considering Scour-Hole Dimensions
}

\author{
Wenbo Tu $\mathbb{D}^{1},{ }^{1}$ Xiaoqiang Gu $\mathbb{D},,^{2,3}$ Xianfeng $M a\left(\mathbb{D},{ }^{2,4}\right.$ and Dawei Huang $\mathbb{D}^{1}$ \\ ${ }^{1}$ School of Civil Engineering and Architecture, East China Jiaotong University, Nanchang 330013, China \\ ${ }^{2}$ Department of Geotechnical Engineering, Tongii University, Shanghai 200092, China \\ ${ }^{3}$ Key Laboratory of Geotechnical and Underground Engineering of Ministry of Education, Tongji University, \\ Shanghai 200092, China \\ ${ }^{4}$ School of Civil Engineering, Kashi University, Kashi 844006, China
}

Correspondence should be addressed to Xianfeng Ma; xf.ma@tongji.edu.cn

Received 6 September 2020; Revised 24 September 2020; Accepted 4 October 2020; Published 17 October 2020

Academic Editor: Xing Ma

Copyright (c) 2020 Wenbo Tu et al. This is an open access article distributed under the Creative Commons Attribution License, which permits unrestricted use, distribution, and reproduction in any medium, provided the original work is properly cited.

\begin{abstract}
As a cross-sea or river deep-water foundation, it is clear that the caisson foundation will be subjected to significant lateral dynamic loads due to winds or waves and suffer from scouring under its long-term effect. In order to obtain the scour effect on the dynamic response of the foundation, an analytical model describing the scour-hole effect in terms of scour depth, scour width, and slope angle was constructed. Combined with the nonlinear Winkler theory, a method for the dynamic response of the caisson foundation considering the scour-hole dimensions was proposed. Comparisons against the results from the dynamic FEM demonstrate the reliability of this method. The effects of the scour width, slope angle, and scour depth on the dynamic response of the caisson were discussed. The results show that the scour depth affects the dynamic displacement and resonant frequency of the foundation most, whereas the scour width does less and the slope angle does the least; the dynamic response of caisson can be approximated as the case of the slope angle $5^{\circ}$ and the scour width $5 B$ when the slope angle is less than $5^{\circ}$ and the scour width is greater than $5 B$, respectively; the effects of scour width and slope angle on the dynamic response of caisson have the similar change pattern in the displacement and resonant frequency when the scour depth is different. However, the effect of amplitude on dynamic response shows a nonlinear increase trend when the scour depth is relatively large.
\end{abstract}

\section{Introduction}

Caisson is a common foundation type which is suitable for bridge engineering. It is widely used in cross-river and crosssea bridges because of its strong integrity and large bearing capacity, such as the Shanghai-Nantong Yangtze River Bridge in China, the Brooklyn Bridge in the United States, and the Akashi Strait Bridge in Japan [1]. Comparing with the traditional foundation on land, the working environment of caisson foundation is more complicated. The caisson foundation not only needs to withstand the upper vertical load but also needs to withstand the horizontal dynamic load such as wind, wave currents, and possible earthquakes. Research has also shown that the mechanism of lateral interaction is more complicated than that of vertical interaction and the lateral load takes more significant effect on the characteristics of foundation than vertical load [2]. Therefore, more strict requirements are put forward for the horizontal dynamic performance of the caisson foundation during the design and construction. In addition, the caisson foundation easily suffers from scouring due to the huge size resulting in a drastic change in the water crossing section. Take the caisson foundation used in the Taizhou Yangtze River Bridge as an example - the length, width, and height of the caisson is $58.2 \mathrm{~m}, 44.1 \mathrm{~m}$, and $76 \mathrm{~m}$, respectively. According to the field measurement data, the maximum local scour depth reaches $17.4 \mathrm{~m}$ about one year after the completion of construction, and the scour depth comes to a new peak value of $46.6 \mathrm{~m}$ according to the laboratory tests when the factors such as water velocity, flow, and angle are 
taken into account $[3,4]$. Obviously, such a huge scour depth value will inevitably cause significant changes in the bearing performance and dynamic characteristics of the foundation and may even cause the damage of bridge foundation. Based on the statistics data of 584 bridge accidents from 1813 to 2018 [5], it is concluded that about $30 \%$ of bridge collapses are related to natural disasters, and bridge scouring caused by floods is the most common case. Therefore, it is necessary to study the changes in the characteristics of the caisson foundation before and after scouring.

In recent years, there is a growing concern on the characteristics of caisson foundation before and after scouring. Liu et al. [6] studied the horizontal bearing characteristics of the suction caisson after scouring in layered clay soils. Zhang et al. [7] conducted a laboratory test to investigate the lateral response of the caisson and its dependence on the characteristics of the applied cyclic load and scouring. However, these methods for analyzing the scour effect mentioned above focused on the static behavior of the foundation, and the dynamic behavior of the foundation was not involved. Tu et al. [8,9] discussed the influence of scouring on dynamic impedance and resonant characteristics of the caisson, but the scour pattern is assumed to be of layer distribution mode. Nevertheless, it is well recognized that scour holes formed around the caisson usually involve certain shapes and sizes $[10,11]$, and the static and dynamic characteristics of the foundation is affected by the shape and size of scour holes [12, 13]. Yang et al. [14] analyzed the effect of scour-hole dimensions on the response of laterally loaded piles based on the modified strain wedge method. Zhang et al. [15] used Mindlin's solution to analyze the influence of the scour-hole dimension on the horizontal bearing characteristics of a single pile. However, the caisson is different from the pile foundation; hence, Mindlin's solution cannot be directly used for scour analysis due to the large size of the caisson foundation. To get a better understanding of the scour effect, it is necessary to study the dynamic characteristics of foundations in combination with the dimension of scour holes.

The objective of this paper is to propose a simplified model for the analysis of laterally loaded caisson foundations under scouring, which can account for the effects of scourhole dimensions on the dynamic performance of foundations. In order to verify the proposed simplified model for the lateral vibration of the scoured caisson, 3D finite element simulations are conducted and good agreements are obtained between the results of the numerical method and the theoretical model. Finally, to provide a reference for engineering application, the influence of the scour depth, scour width, and scour slope angle of scour holes on the dynamic characteristics of the caisson foundation are studied based on the proposed model.

\section{Lateral Dynamic Analysis Model for the Scoured Caisson}

2.1. Analysis Model for Caisson in Layered Soils. Based on the Winkler dynamic analysis theory, a two-dimensional plane analysis model of caisson in a homogeneous elastic foundation without any scouring can be established, as shown in Figure 1 [16]. Here, the caisson is assumed to be a rigid embedded foundation. For a caisson subjected to the harmonic horizontal load $Q_{0}$ and moment $M_{0}$ at the top center of the foundation, the lateral dynamic equilibrium equation can be expressed as

$$
\left[M_{b}\right]\left\{\begin{array}{l}
\ddot{u}_{b} \\
\ddot{\theta}_{b}
\end{array}\right\}+\left[C_{b}\right]\left\{\begin{array}{l}
\dot{u}_{b} \\
\dot{\theta}_{b}
\end{array}\right\}+\left[K_{b}\right]\left\{\begin{array}{l}
u_{b} \\
\theta_{b}
\end{array}\right\}=\left\{\begin{array}{c}
Q_{0} \\
Q_{0} D+M_{0}
\end{array}\right\},
$$

where $D$ is the height of the foundation, and $u_{b}$ and $\theta_{b}$ are the horizontal displacement and the rotation angle of the base center of the foundation. $\left[M_{b}\right],\left[K_{b}\right]$, and $\left[C_{b}\right]$ are the mass dynamic matrix, stiffness matrix, and damping matrix of the foundation, respectively. They can be rewritten as

$$
\begin{aligned}
{\left[M_{b}\right] } & =\left[\begin{array}{cc}
m & m h_{1} \\
m h_{1} & J_{c}+m h_{1}^{2}
\end{array}\right], \\
{\left[K_{b}\right] } & =\left[\begin{array}{ll}
K_{h h} & K_{h r} \\
K_{r h} & K_{r r}
\end{array}\right], \\
{\left[C_{b}\right] } & =\left[\begin{array}{ll}
C_{h h} & C_{h r} \\
C_{r h} & C_{r r}
\end{array}\right],
\end{aligned}
$$

where $m$ is the mass of caisson foundation, $h_{1}$ is the distance from the center of gravity to the base surface of the caisson, and $J_{c}$ is the mass moment of inertia of the caisson. $K_{h h}, K_{r r}$, and $K_{h r}\left(K_{r h}\right)$ are the horizontal dynamic stiffness, rocking dynamic stiffness, and coupled horizontal-rocking dynamic stiffness of caisson, respectively. $C_{h h}, C_{r r}$, and $C_{h r}\left(C_{r h}\right)$ are the horizontal dynamic damping, rocking dynamic damping, and coupled horizontal-rocking dynamic damping of caisson, respectively:

$$
\begin{aligned}
& K_{h h}=K_{h}+\sum_{i=1}^{n} k_{x i} d_{i}, \\
& K_{h r}=K_{r h}=\sum_{i=1}^{n} k_{x i} d_{i} z_{i}, \\
& K_{r r}=K_{r}+\sum_{i=1}^{n}\left[k_{x i} d_{i}\left(z_{i}^{2}+\frac{1}{12} d_{i}^{2}\right)+k_{r i} d\right], \\
& C_{h h}=C_{h}+\sum_{i=1}^{n} c_{x i} d_{i}, \\
& C_{h r}=C_{r h}=\sum_{i=1}^{n} c_{x i} d_{i} z_{i}, \\
& C_{r r}=C_{r}+\sum_{i=1}^{n}\left[c_{x i} d_{i}\left(z_{i}^{2}+\frac{1}{12} d_{i}^{2}\right)+c_{r i} d\right],
\end{aligned}
$$

where $z_{i}$ is the distance from the center of layer $i$ to the soil surface, $d_{i}$ is the thickness of soil layer $i$, and $d$ is the embedment depth of the caisson. $K_{h}, C_{h}$ and $K_{r}, C_{r}$ are the horizontal and rotational spring stiffness and damping 


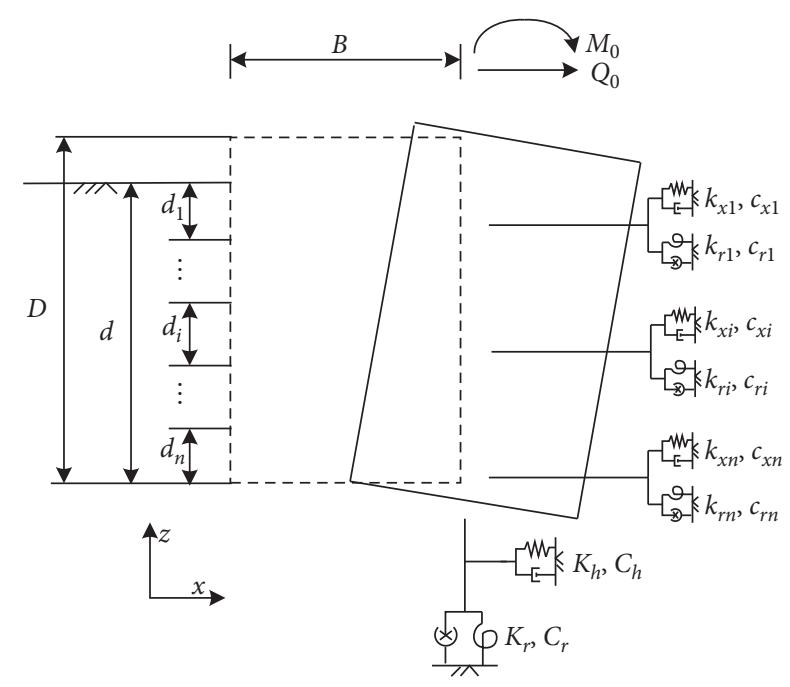

Figure 1: Dynamic Winkler model for the lateral vibration of the caisson.

coefficient of the concentrated springs with respect to the bottom of the caisson, respectively. $k_{x i}, c_{x i}$ and $k_{r i}, c_{r i}$ are the stiffness and damping coefficient of the distributed horizontal and rocking springs of layer $i$ ( $i$ ranges from 1 to $n$ ), respectively. $k_{x i}, c_{x i}$, and $k_{r i}, c_{r i}$ are given in Appendix $\mathrm{A}$ in detail.

2.2. Simplified Method considering the Scour-Hole Dimensions. During the analysis of the scour effect, most of the studies assume that the loss of soil around the foundation is distributed in a plane mode. In reality, the scour pattern is in irregular shape, which is significantly affected by some factors, such as the water velocity and foundation type. Generally, the scour pattern at a certain state can be approximated by scour depth $S_{d}$, scour width $S_{w}$, and scour slope angle $\theta$, as shown in Figure $2[12,15]$. According to the symmetry of the model, the illustration of stress loss around the caisson is shown in Figure 3.

For a caisson embedded in clay, the mean effective stress $\sigma_{\mathrm{m}}^{\prime}$ at a certain point before scouring can be determined as

$$
\sigma_{\mathrm{m}}^{\prime}=\frac{\left(1+2 K_{0}\right) \gamma_{0}^{\prime} h_{0}}{3}
$$

where $\gamma_{0}^{\prime}$ and $h_{0}$ are the effective unit weight of soil and the embedded depth, respectively. $K_{0}$ is the coefficient of earth pressure at rest.

According to Figure 3, with the formation of the scour hole, the mean effective stress at a certain state can be expressed as

$$
\sigma_{\mathrm{ms}}^{\prime}=\sigma_{\mathrm{m}}^{\prime}-\sigma_{\mathrm{ul}}^{\prime}
$$

where $\sigma_{\mathrm{ms}}^{\prime}$ is the mean effective stress after scouring, and $\sigma_{\mathrm{ul}}^{\prime}$ is the stress loss caused by the unloading of the soil when the scour hole is formed.

Based on the plane strain hypothesis, the stress loss of the point of interest around the caisson shaft after scouring can be calculated by the superposition principle. It can be approximately expressed as the sum of the stress loss caused by the triangular scour hole "abc" and the quadrilateral scour hole "bcde," as shown in Figure 3. Then, taking point "a" as the origin of coordinates to establish local coordinates, the vertical stress loss and lateral stress loss of the point of interest can be given as [17]

$$
\begin{gathered}
\sigma_{z}^{\prime}=\frac{2 \gamma_{0}^{\prime} S_{d} h_{0}^{3}}{\pi} \int_{S_{d} / \tan \theta}^{2 S_{w}+S_{d} / \tan \theta} \frac{1}{\left[\left(S_{w}+S_{d} / \tan \theta-x\right)^{2}+h_{0}^{2}\right]^{2}} \mathrm{~d} x+\frac{2 \gamma_{0}^{\prime} h_{0}^{3} \tan \theta}{\pi} \int_{0}^{S_{d} / \tan \theta} \frac{x}{\left[\left(S_{d} / \tan \theta\right)^{2}+h_{0}^{2}\right]^{2}} \mathrm{~d} x, \\
\sigma_{x}^{\prime}=\frac{4 \gamma_{0}^{\prime} S_{d} h_{0}}{\pi} \int_{S_{w}+S_{d} / \tan \theta}^{S_{d} / \tan \theta} \frac{\left(S_{w}+S_{d} / \tan \theta\right)^{2}}{\left[\left(S_{w}+S_{d} / \tan \theta-x\right)^{2}+h_{0}^{2}\right]^{2}} \mathrm{~d} x+\frac{4 \gamma_{0}^{\prime} h_{0} \tan \theta}{\pi} \int_{0}^{S_{d} / \tan \theta} \frac{\left(S_{d} / \tan \theta-x\right)^{2} x}{\left[\left(S_{d} / \tan \theta-x\right)^{2}+h_{0}^{2}\right]^{2}} \mathrm{~d} x
\end{gathered}
$$

where $\sigma_{z}^{\prime}$ and $\sigma_{x}^{\prime}$ are the vertical and lateral stress loss of the point of interest, respectively. $S_{d}, S_{w}$, and $\theta$ are the scour depth, scour width, and scour slope angle of the scour hole, respectively. $x$ is the coordinate of the location from point "a" to "d," as shown in Figure 3.

The mean effective stress $\sigma_{\mathrm{ms}}^{\prime}$ after scouring obtained by putting equations (4)-(7) together can be expressed as

$$
\sigma_{\mathrm{ms}}^{\prime}=\frac{\left(1+2 K_{0}\right) \gamma_{0}^{\prime} h_{0}}{\left(3-\left(\sigma_{z}^{\prime}+2 \sigma_{x}^{\prime}\right)\right) / 3} .
$$

With the formation of the sour hole, the soil around the caisson also changed from a normal consolidated state to an overconsolidated state. As the change of the gravity of soil is limited, the OCR can be expressed as

$$
\text { OCR }=\frac{\gamma_{0}^{\prime} h_{0}}{\gamma_{0}^{\prime} h_{0}-\sigma_{z}^{\prime}} .
$$

In the meantime, the stress loss of the soil around the caisson will also cause a change in void ratio, and the change value in void ratio $\Delta e$ is given as

$$
\Delta e=e_{0 \mathrm{~s}}-e_{0}=-\kappa \ln \left(\frac{\sigma_{\mathrm{ms}}^{\prime}}{\sigma_{\mathrm{m}}^{\prime}}\right),
$$

where $e_{0}$ and $e_{0 \mathrm{~s}}$ are the void ratio before and after scouring, respectively; and $\kappa$ is the swelling index from an isotropic consolidation test. 


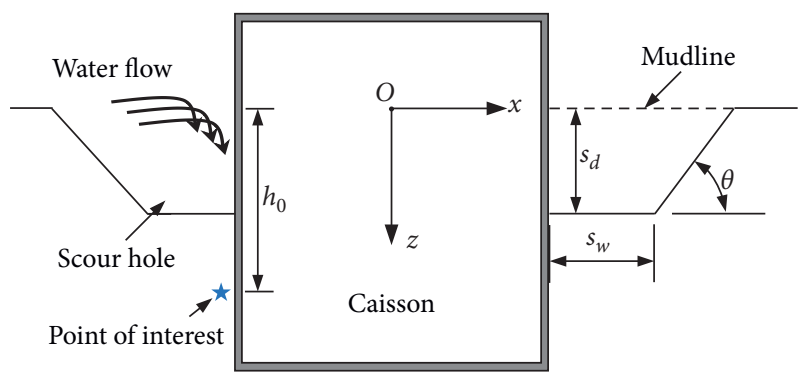

FIgURE 2: Illustration of the scour hole around the caisson foundation.

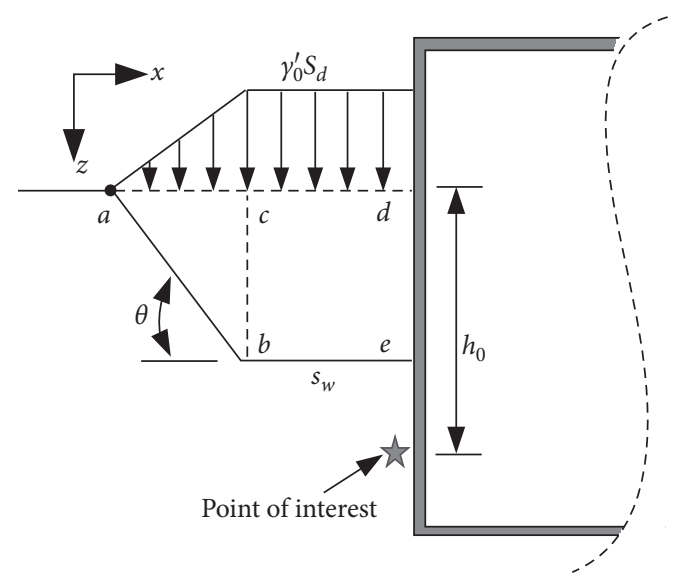

FIGURE 3: Illustration of scour-hole stress loss.

By putting equations (4) and (8) together, $\Delta e$ can be rewritten as

$$
\Delta e=-\kappa \ln \left[\frac{\left(1+2 K_{0}\right) \gamma_{0}^{\prime} h_{0}-\left(\sigma_{z}^{\prime}+2 \sigma_{x}^{\prime}\right)}{\left(1+2 K_{0}\right) \gamma_{0}^{\prime} h_{0}}\right] .
$$

In addition, the shear modulus of soil is related to the mean effective stress, void ratio, and overconsolidation ratio (OCR). For normally consolidated clay, it can be taken as $[18,19]$

$$
G_{0}=3230 \frac{\left(2.97-e_{0}\right)^{2}}{1+e_{0}}(O C R)^{k}\left(\sigma_{\mathrm{m}}^{\prime}\right)^{0.5}
$$

where $k$ is the parameter related to the plasticity index, equal to 0.18 as suggested in [19].

After scouring, the shear modulus of soil can be rewritten as

$$
G_{0 \mathrm{~s}}=3230 \frac{\left(2.97-e_{0 \mathrm{~s}}\right)^{2}}{1+e_{0 \mathrm{~s}}}\left(\frac{\gamma_{0}^{\prime} h_{0}}{\gamma_{0}^{\prime} h_{0}-\sigma_{z}^{\prime}}\right)^{k}\left(\sigma_{\mathrm{ms}}^{\prime}\right)^{0.5} .
$$

Generally, the soil around the caisson foundation shows nonlinear characteristics in practical engineering. In order to consider the nonlinear characteristics of the soil with the change of soil strain and the change of cyclic loading and unloading, the hyperbolic stress-strain relationship model was introduced to modify the proposed model:

$$
\tau(\gamma)=\frac{G_{0} \cdot \gamma}{G_{0} \cdot \gamma /\left(S_{u}+1\right)},
$$

where $G_{0}$ is the shear modulus of soil, $\tau(\gamma)$ is the shear stress, and $S_{\mathrm{u}}$ is the undrained shear strength. $\gamma$ is shear strain of soil, which can be approximated by the following equation [20]:

$$
\gamma=\frac{1+v}{2.5 B} y,
$$

where $y$ is the lateral displacement of the foundation, $v$ is Poisson's ratio of soil, and $B$ is the diameter of the foundation.

The hysteretic curves of shear stress and strain obtained by Masing's rules are used to simulate the loading, reloading, and unloading, which is expressed as

$$
\tau \pm \tau_{\mathrm{ur}}=\frac{\gamma \pm \gamma_{\mathrm{ur}}}{1 / G_{0}+\left|\gamma \pm \gamma_{\mathrm{ur}}\right| /\left(2 \tau_{f}\right)},
$$

where $\gamma_{\mathrm{ur}}$ and $\tau_{\mathrm{ur}}$ are the current shear strain and shear stress at the onset of unloading or reloading, and $\tau_{f}$ is the shear stress at failure, given as [19]

$$
\tau_{\mathrm{f}}=\left[\left(\frac{1+K_{0}}{2} \sigma_{v}^{\prime} \sin \varphi^{\prime}+c \cos \varphi^{\prime}\right)^{2}-\left(\frac{1-K_{0}}{2} \sigma_{v}^{\prime}\right)^{2}\right]^{0.5},
$$

where $\sigma_{v}^{\prime}$ is the vertical effective stress of soil, and $c$ and $\varphi^{\prime}$ are the cohesive force and effective internal friction angle of soil, respectively.

The key to calculating the dynamic stiffness matrix $\left[K_{b}\right]$ and damping matrix $\left[C_{b}\right]$ is to determine the stiffness coefficient $k_{x i}, k_{r i}$ and the damping coefficient $c_{x i}, c_{r i}$, which are closely related to the shear modulus of soil. Once the soil parameters, such as the effective unit weight of soil $\gamma_{0}^{\prime}$ and void ratio $e_{0}$, are determined, the stiffness coefficients $k_{x i}, k_{r i}$ and the damping coefficients $c_{x i}, c_{r i}$ at a certain scour state with scour depth $S_{d}$, scour width $S_{w}$, and scour slope angle $\theta$ can be re-examined by equation (13). Then, the dynamic response of a caisson subjected to the lateral load can be calculated based on the proposed model.

\section{Verification of the Proposed Model}

A numerical simulation presented herein demonstrates the application of the proposed method for the lateral response of the caisson. The height, embedded depth, and diameter of the caisson are $120 \mathrm{~m}, 70 \mathrm{~m}$, and $90 \mathrm{~m}$, respectively, embedded in cohesive soil stratum. Young's modulus, Poisson's ratio, and mass density of the concrete caisson are $36 \mathrm{GPa}$, 0.3 , and $2600 \mathrm{~kg} / \mathrm{m}^{3}$, respectively. The thickness of the top, bottom, and side walls of caisson are $3.0 \mathrm{~m}$. The density, initial void ratio, Poisson's ratio, and undrained shear strength of soil around the caisson are $1600 \mathrm{~kg} / \mathrm{m}^{3}, 0.7,0.49$, and $100 \mathrm{kPa}$, respectively. It is assumed that the scour depth $S_{d}$, the scour width $S_{w}$, and the scour slope angle $\theta$ around the caisson foundation are $20 \mathrm{~m}, 18 \mathrm{~m}$, and $30^{\circ}$, respectively. According to the symmetry principle, half of the meshing model is depicted in Figure 4, where the model sizes are 


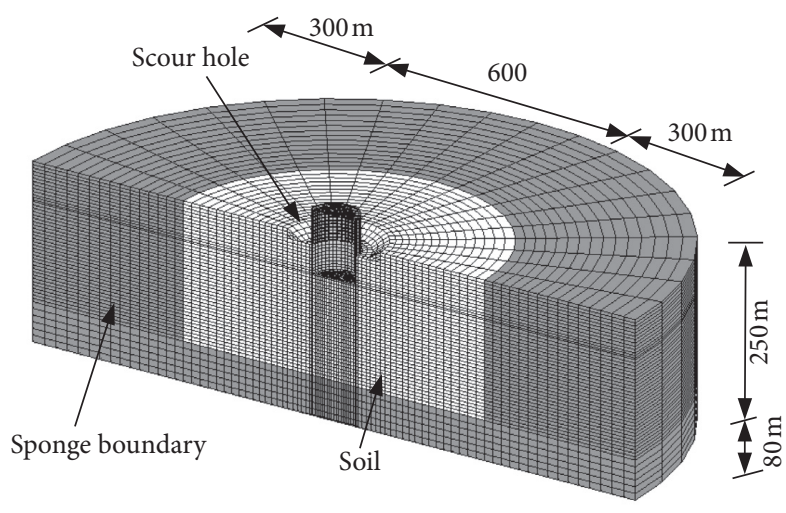

FIGURE 4: FEM model of caisson foundation.

marked. During the dynamic finite element calculation, the boundary processing is an important factor affecting the accuracy of the results. Here, the sponge boundary is adopted to attenuate the wave reflection in the dynamic finite element analysis, which was proposed by Varun et al. [21]. The gray elements enveloping the soil and caisson elements are the sponge boundary elements. It is believed that the purpose of attenuating the wave reflection can be achieved by changing the Rayleigh damping parameters within the sponge layer and the thickness of the sponge boundary layer [21]. Based on this fundamental, the Rayleigh damping parameters are selected 10.5 and 0.0105 , and boundary thickness in this example is determined as $300 \mathrm{~m}$. Then, the resulting amplitude reduction of $P$ wave and $S$ wave with frequency can be described by the curves in Figure 5. It can be seen that the higher the frequency, the more the energy of the wave being absorbed by the sponge boundary.

In order to consider the soil nonlinearity around the caisson, a hyperbolic stress-strain curve has been used in the simplified theoretical model. However, the constitutive model of soil in the finite element method (FEM) is usually selected as ideal elastoplastic, which is different from the hyperbolic stress-strain relationship used in the theoretical model. Therefore, the hyperbolic stress-strain characteristics in the FEM are simulated by the method of importing yield stress and plastic strain, and the hyperbolic hardening law can be defined by a multisegment line [22]. The yield stress and corresponding plastic strain within the embedded depth of the caisson before and after scouring are shown in Table 1 .

Here, the caisson subjected to lateral harmonic loads $200 \mathrm{MN}$ is used to compare the dynamic responses by considering the soil nonlinearity effect. The dynamic response curves of the top displacement of the caisson before and after scouring at different frequencies are calculated by the FEM. Comparison with the theoretical results are shown in Figure 6. It can be seen that the result of the simplified method is slightly larger than the FEM results, but the trend of the theoretical results is close to that of the FEM results, which indicates the rationality of the simplified method. In the meantime, the dynamic displacement of the caisson foundation before and after scouring both have a resonance peak value under the different frequencies of vibration loads.

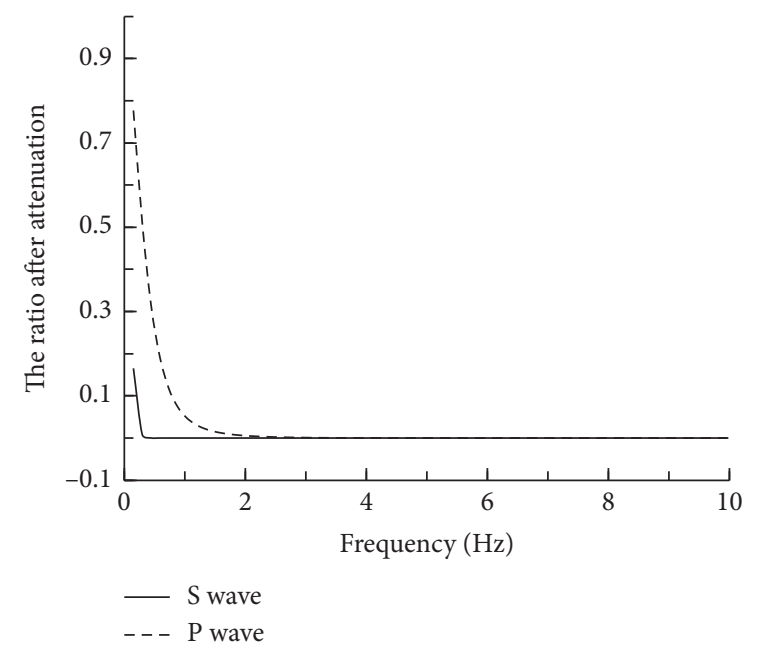

Figure 5: Absorption of $S$ and $P$ waves at the sponge boundary.

TABLE 1: Yield stresses and corresponding plastic strains at different embedded depths.

\begin{tabular}{|c|c|c|c|c|c|}
\hline \multicolumn{2}{|c|}{ Yield stress $(\mathrm{kPa})$} & 40 & 120 & 160 & 195 \\
\hline \multirow{4}{*}{$\begin{array}{l}\text { Before scouring } \\
\int d_{\varepsilon}^{\text {sp }}\end{array}$} & $0-20 \mathrm{~m}$ & $2.8 e-5$ & $5.1 e-4$ & 0.0018 & 0.021 \\
\hline & $20-40 \mathrm{~m}$ & $1.4 e-5$ & $2.6 e-4$ & $9.2 e-4$ & 0.011 \\
\hline & $40-60 \mathrm{~m}$ & $1.1 e-5$ & $2.0 e-4$ & $7.2 e-4$ & 0.009 \\
\hline & $\begin{array}{l}\text { Below } \\
60 \mathrm{~m}\end{array}$ & 9. & 4 & -4 & 0.008 \\
\hline \multirow{3}{*}{$\begin{array}{l}\text { After scouring } \\
\int d_{\varepsilon}^{\text {sp }}\end{array}$} & $0-20 \mathrm{~m}$ & $2.5 e-5$ & $4.5 e-4$ & 0.0016 & 0.019 \\
\hline & $20-40 \mathrm{~m}$ & $1.3 e-5$ & $2.5 e-4$ & $8.8 e-4$ & 0.010 \\
\hline & $\begin{array}{l}\text { Below } \\
40 \mathrm{~m}\end{array}$ & $1.1 e-5$ & $2.0 e-4$ & $7.3 e-4$ & 0.009 \\
\hline
\end{tabular}

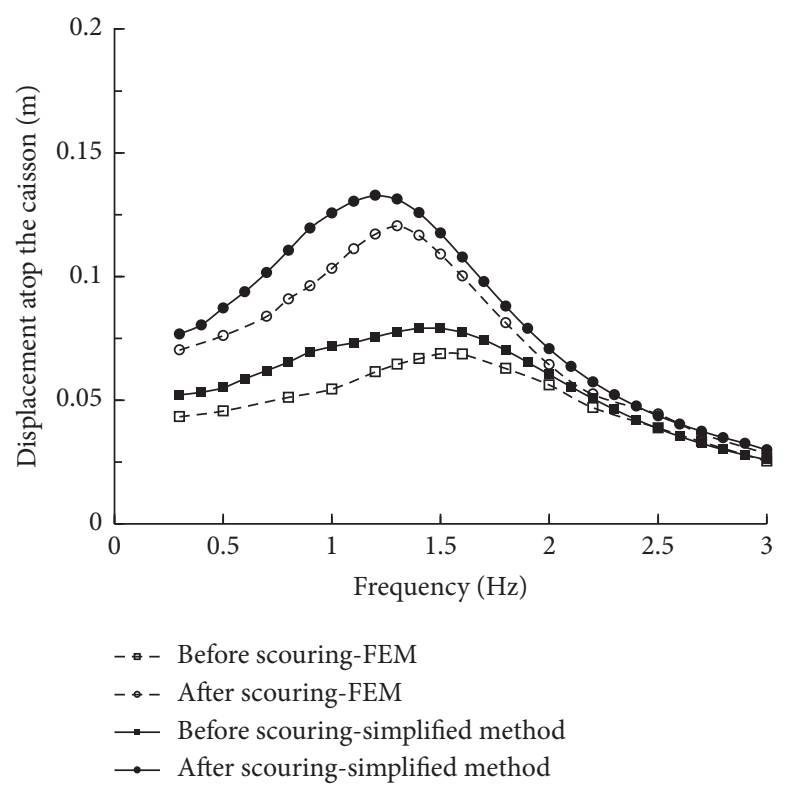

Figure 6: Dynamic response of caisson before and after scouring.

Notice that the displacement amplitude after scouring shows an increasing trend compared with that before scouring, while the resonant frequency shows a decreasing trend. The maximum displacement deviation between the results of the 
simplified method and the FEM after scouring is about $13.3 \%$. This is partly attributed to the limitation of the plane strain assumption in considering three-dimensional problems, which slightly magnifies the stress loss caused by the scour hole. Finally, time histories of lateral displacement atop the caisson when the frequency equals to $1.4 \mathrm{~Hz}$ before scouring and the frequency equal to $1.2 \mathrm{~Hz}$ after scouring have been extracted to make a further comparison between the FEM and the proposed simplified method, as shown in Figures 7 and 8 . These comparisons show that the simplified method agrees well with the FEM, ensuring the reliability of the simplified method.

\section{Simulation of the Scour Holes and Parametric Study}

In order to further explore the effect of the scour hole on the lateral dynamic characteristics of the caisson foundation, the caisson foundation adopted in the FEM is used for analysis. A parametric study was conducted to evaluate the effects of scour depth, scour width, and scour slope angle on the responses of the caisson. The scour width varied from $0.2 B$, $B, 5 B$ to $10 B$, whereas the scour depth $\left(S_{d}=0.3 d\right)$ and scourhole slope angle $\left(\theta=30^{\circ}\right)$ were kept unchanged. Four scour slope angles $\left(\theta=1^{\circ}, 5^{\circ}, 10^{\circ}\right.$, and $\left.30^{\circ}\right)$ were considered to evaluate their effects on the responses of caisson when the scour depth was $0.3 d$ and the scour width was $0.2 B$. Three scour depths $\left(S_{d}=0.15 d, 0.3 d\right.$, and $\left.0.45 d\right)$ were investigated when the scour width was $0.2 B$ and the scour-hole slope angle was $30^{\circ}$. The corresponding working conditions of scouring are summarized in Table 2. Here, $S_{w}=0.2 B(18 \mathrm{~m})$, $\theta=30^{\circ}$, and $S_{d}=0.3 d(20 \mathrm{~m})$ were selected as reference values.

4.1. Effect of Scour Width. Figure 9 shows the dynamic lateral displacement atop the caisson after scouring as a function of the frequency computed by the simplified method at four different scour widths. It can be seen that the dynamic displacement increased significantly with scour width at an accelerating rate. The percentage increases in the peak value of the displacement compared with the no scouring condition are $70.1 \%, 112.7 \%, 141.7 \%$, and $146.8 \%$ when scour width varied from $0.2 B$ to $10 B$. The total amplitude change in the peak displacement caused by the scour width is about $76.7 \%$. It can also be found that the resonant frequency of the foundation changes very little under different scouring widths. The resonant frequency and the peak value of the displacement when the scour width was $5 B$ are basically the same as when the scour width was $10 B$, which indicates that the effect of the scour width was found to be the same as that at complete removal of the soil layer when the scour width was greater than $5 B$. This phenomenon can also be observed from the stress-strain hysteresis curves of the surface soil around the caisson under different scour widths, as shown in Figure 10 . The stress-strain curve gradually slopes downward as the scour width increases, and the peak value of curves approached a constant when the scour width exceeded $5 B$. Therefore, it can be known that the traditional

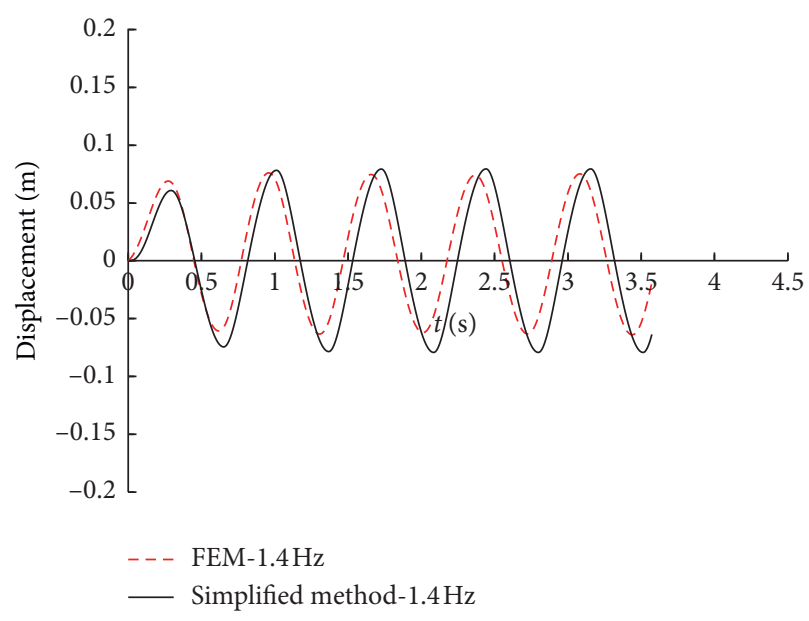

FIgURE 7: Time histories of lateral displacement atop the caisson before scouring.

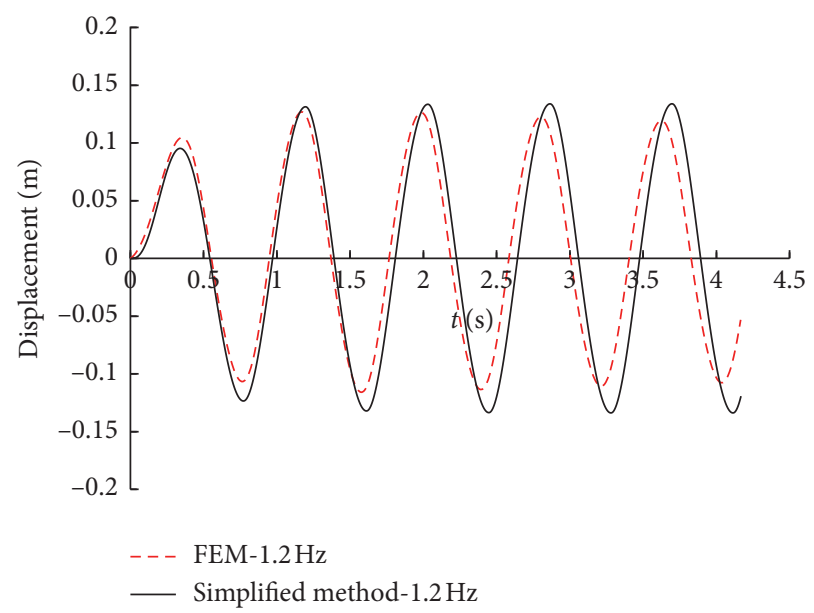

Figure 8: Time histories of lateral displacement atop the caisson after scouring.

TABLE 2: Working conditions of scouring.

\begin{tabular}{lcccc}
\hline \multicolumn{1}{c}{ Working conditions } & & $S_{d}$ & $S_{w}$ & $\theta$ \\
\hline \multirow{4}{*}{ Variation of scour width } & W1 & $0.3 d$ & $0.2 B$ & $30^{\circ}$ \\
& W2 & $0.3 d$ & $B$ & $30^{\circ}$ \\
& W3 & $0.3 d$ & $5 B$ & $30^{\circ}$ \\
& W4 & $0.3 d$ & $10 B$ & $30^{\circ}$ \\
\hline \multirow{5}{*}{ Variation of scour slope angle } & A1 & $0.3 d$ & $0.2 B$ & $1^{\circ}$ \\
& A2 & $0.3 d$ & $0.2 B$ & $5^{\circ}$ \\
& A3 & $0.3 d$ & $0.2 B$ & $10^{\circ}$ \\
& A4 & $0.3 d$ & $0.2 B$ & $30^{\circ}$ \\
\hline \multirow{3}{*}{ Variation of scour depth } & S1 & $0.15 d$ & $0.2 B$ & $30^{\circ}$ \\
& S2 & $0.3 d$ & $0.2 B$ & $30^{\circ}$ \\
& S3 & $0.45 d$ & $0.2 B$ & $30^{\circ}$ \\
\hline
\end{tabular}

method of completely removing the soil layer is conservative for the scouring analysis. The percentage difference of the peak value of the dynamic displacement atop the caisson between case W1 and case W4 can reach $45.4 \%$. 


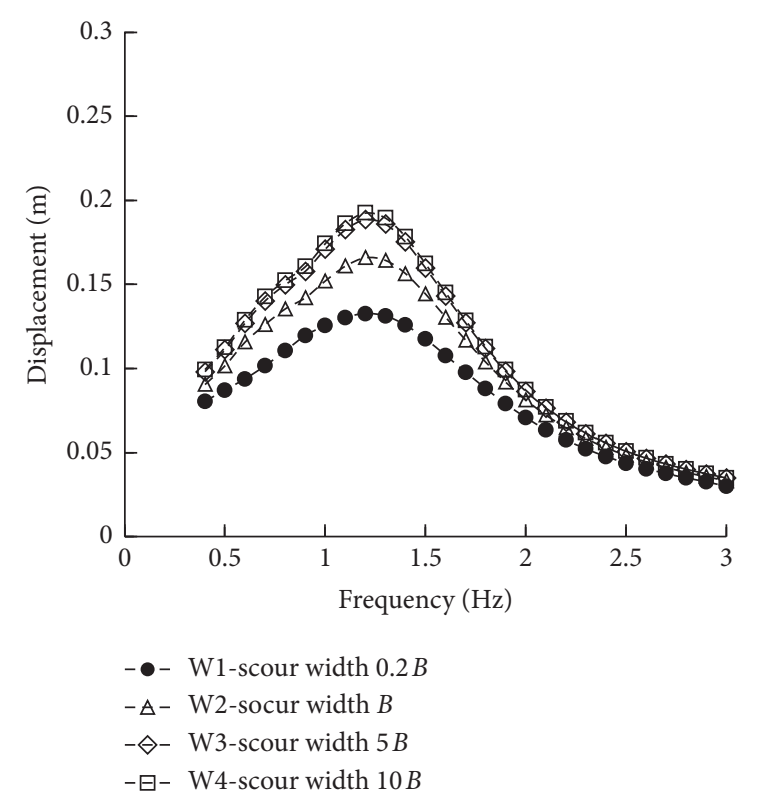

Figure 9: Dynamic response of caisson foundation under different scour widths.

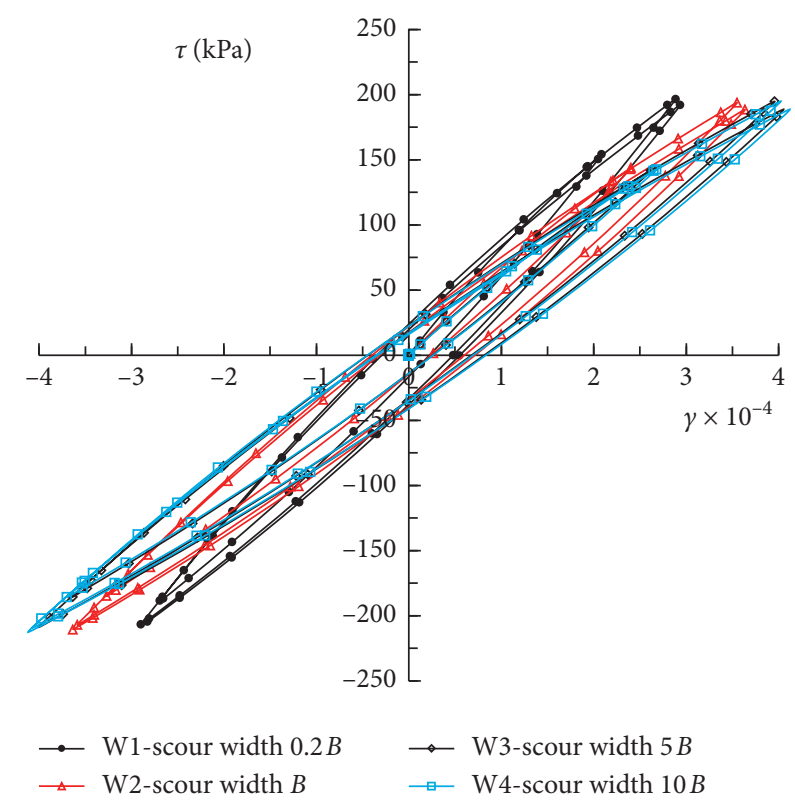

FIgURE 10: Stress-strain hysteresis loops of the surface soil under different scour widths.

4.2. Effect of Scour Slope Angle. The effects of the scour-hole slope angle on the dynamic lateral displacement atop the caisson are shown in Figure 11. An increase in the scour-hole slope angle decreased the dynamic response of the caisson. The percentage increases in the peak value of the displacement compared with the no scouring condition are $70.1 \%, 90.5 \%, 111.7 \%$, and $129.4 \%$ when the scour slope angle varied from $30^{\circ}$ to $1^{\circ}$. A decrease in the slope angle from $30^{\circ}$ to $1^{\circ}$ results in an increase in the displacement by approximately $59.3 \%$. This stems from the fact that a smaller scour-hole slope angle means less overburden soil remaining

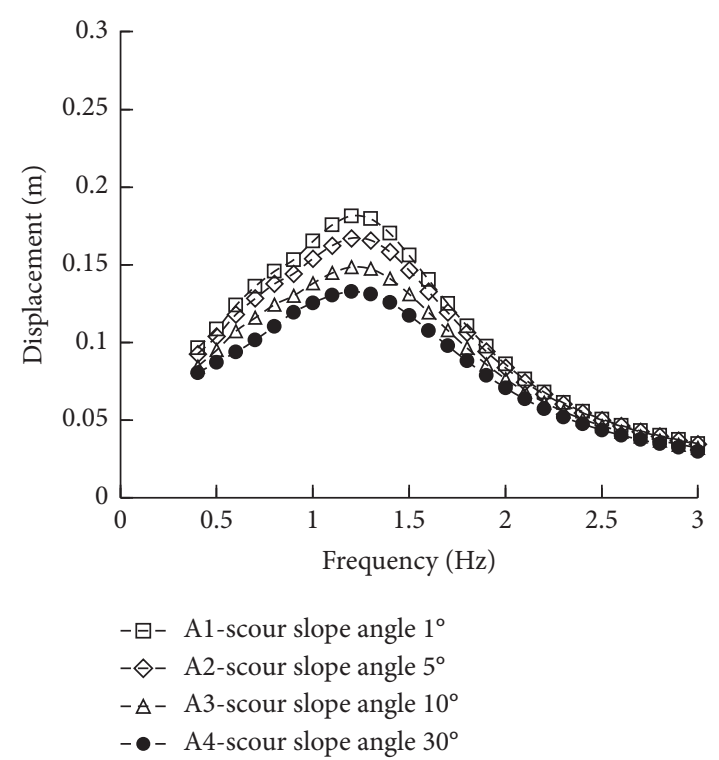

Figure 11: Dynamic response of caisson foundation under different scour slope angles.

above the post scour groundline, consequently, more soil resistance is induced. Similar to the previous comparisons, it can also be found that the dynamic response of case A1 almost coincided with that of case A2, and the maximum difference of displacement between case $\mathrm{A} 1$ and case $\mathrm{A} 2$ is $17.7 \%$, which is relatively small for practical engineering. It can be concluded that the scour slope angle effect could be ignored when the scour slope angle was smaller than or equal to $5^{\circ}$. Compared with the effects of the scour slope angle, the variation of the dynamic response caused by the effect of scour width becomes more notable when scour depths are the same. This similar trend also reflected in the stress-strain hysteresis curves of the soil around the caisson, as shown in Figure 12. The smaller the scour slope angle is, the soil stress-strain hysteresis curve gradually slopes downward, that is, the increase in the strength of soil nonlinearity.

4.3. Effect of Scour Depth. The effects of the scour depth on the dynamic lateral displacement atop the caisson are shown in Figure 13. Here, three different scour depths $0.15 d, 0.3 d$, and $0.45 d$ are discussed. Considering the effect of scour depth on the resonant frequency, the value of resonant frequency gradually decreases with the increase in the scour depth around the caisson, which is different from the effect of the scour width and scour slope angle on the resonant frequency of the foundation; and the percentage increases in the peak value of the displacement compared with the no scouring condition are $14.4 \%, 70.1 \%$, and $242.1 \%$ when scour depth varied from $0.15 d$ to $0.45 d$. It shows an obvious nonlinear increasing trend compared with the effect of scour width and scour slope angle. The main reason for this phenomenon is that the soil loss around the caisson leads to the weakening of the lateral restraint of foundation, and the change of the stress state of the remaining soil may be the 


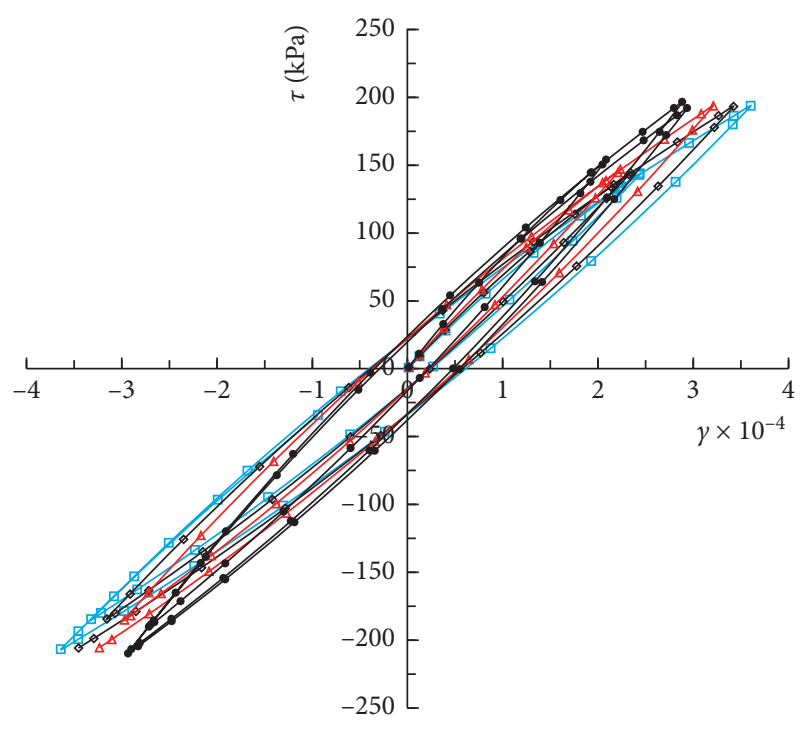

$\rightarrow$ A1-scour slope angle $1^{\circ} \rightarrow \triangle$ A3-scour slope angle $10^{\circ}$

$\rightarrow$ A2-scour slope angle $5^{\circ} \quad \rightarrow$ A4-scour slope angle $30^{\circ}$

FIgURE 12: Stress-strain hysteresis loops of the surface soil under different scour slope angles.

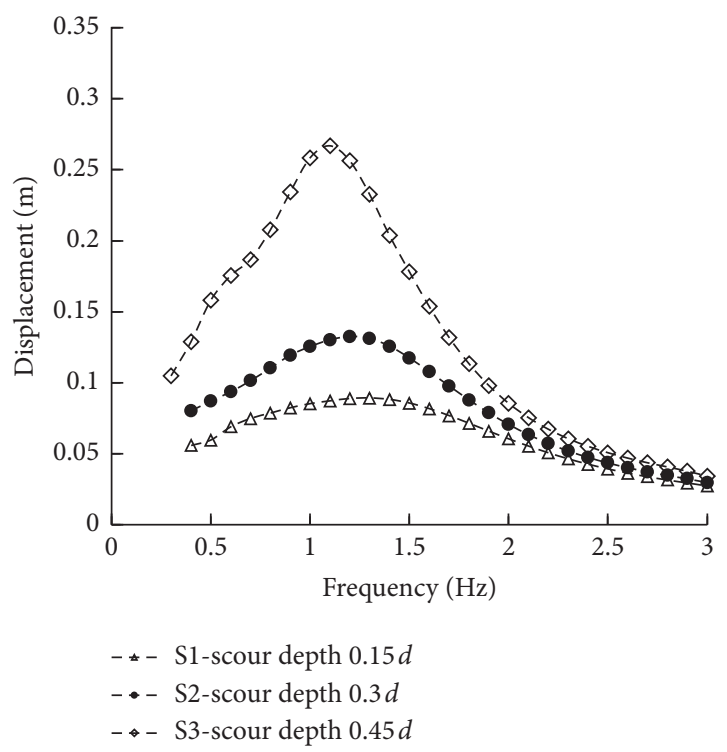

FIgURE 13: Dynamic response of caisson foundation under different scour depths.

second important factor resulting in the increase in the displacement. Figure 14 shows the stress-strain hysteresis curves of the soil around the caisson under different scour depth. It can be seen that the strength of soil nonlinearity is the other factor affecting the dynamic response of the foundation. The greater the scour depth, the larger the strength of the soil nonlinearity around the foundation and the greater the displacement response of the foundation.

From the above analysis, it can be drawn that the scour depth is the most important factor among the three scourhole dimensions (scour depth, scour width, and scour slope angle) influencing the dynamic responses of the laterally

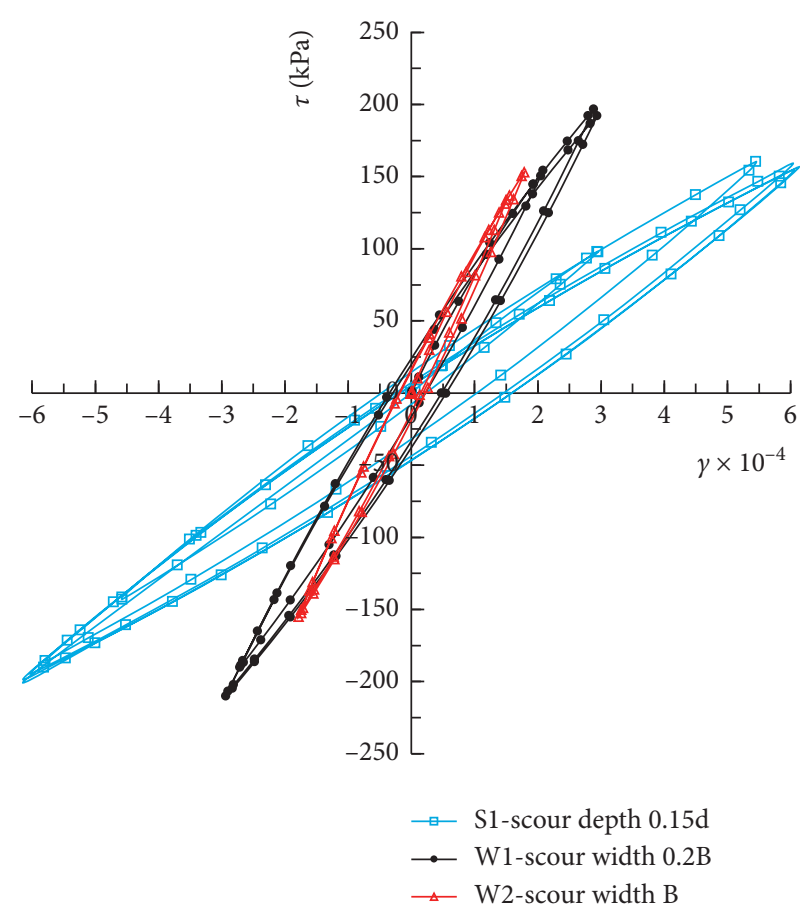

FIGURE 14: Stress-strain hysteresis loops of the surface soil under different scour depths.

loaded foundation. Obviously, it should be worth paying more attention on the effect of scour depth on the dynamic response of the foundation. Whether the effect of the scour slope angle and the scour width on the dynamic characteristics of foundation is still affected by the scour depth should be further investigated. Therefore, the effect of scour slope angle and scour width on the dynamic characteristics of foundation are discussed when the scour depth is $0.15 \mathrm{~d}$ $(10 \mathrm{~m})$. The working conditions are summarized in Table 3 .

The lateral dynamic displacement of the caisson as a function of frequency under different scour widths and scour slope angles are shown in Figures 15 and 16. Compared with Figures 9 and 11, the overall trend of the results is roughly consistent with the change pattern given in Figures 15 and 16; however, the variation amplitude of dynamic responses is significantly reduced with the change of scour width and scour slope angle when scour depth is at a low value. The degree of displacement increase became more notable under a higher scour depth. This is mainly attributed to the small change in the stress state of the soil around the caisson. In the meantime, it can also be found that the scour width effect could be ignored when the width was greater than or equal to $5 B$ and the scour slope angle effect could be ignored when the scour slope angle was less than or equal to $5^{\circ}$.

It is worth noting that there are two major limitations that need to be addressed for the simplified method. First, a gap will occur between the caisson foundation and soil, and this effect was not considered in this simplified method. Second, the proposed model for evaluating the dynamic response of the caisson is based on the plane strain hypothesis, as well as the scour hole around the caisson foundation. More accurate analysis needs to be studied 
TABLE 3: Working conditions with scour depth at $0.15 d$.

\begin{tabular}{ccccc}
\hline Working conditions & & $S_{d}$ & $S_{w}$ & $\theta$ \\
\hline \multirow{4}{*}{ Variation of scour width } & WS1 & $0.15 d$ & $0.2 B$ & $30^{\circ}$ \\
& WS2 & $0.15 d$ & $B$ & $30^{\circ}$ \\
& WS3 & $0.15 d$ & $5 B$ & $30^{\circ}$ \\
& WS4 & $0.15 d$ & $10 B$ & $30^{\circ}$ \\
\hline \multirow{5}{*}{ Variation of scour slope angle } & AS1 & $0.15 d$ & $0.2 B$ & $1^{\circ}$ \\
& AS2 & $0.15 d$ & $0.2 B$ & $5^{\circ}$ \\
& AS3 & $0.15 d$ & $0.2 B$ & $10^{\circ}$ \\
& AS4 & $0.15 d$ & $0.2 B$ & $30^{\circ}$ \\
\hline
\end{tabular}

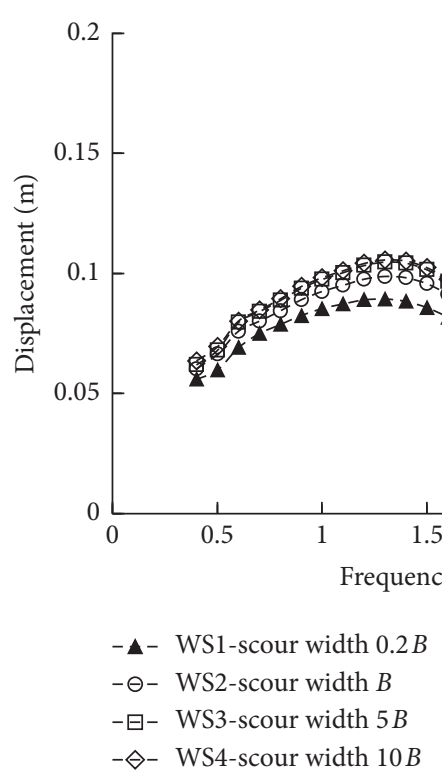

FIGURE 15: Effect of scour width on the dynamic response of caisson foundation $\left(S_{d}=0.15 d\right)$.

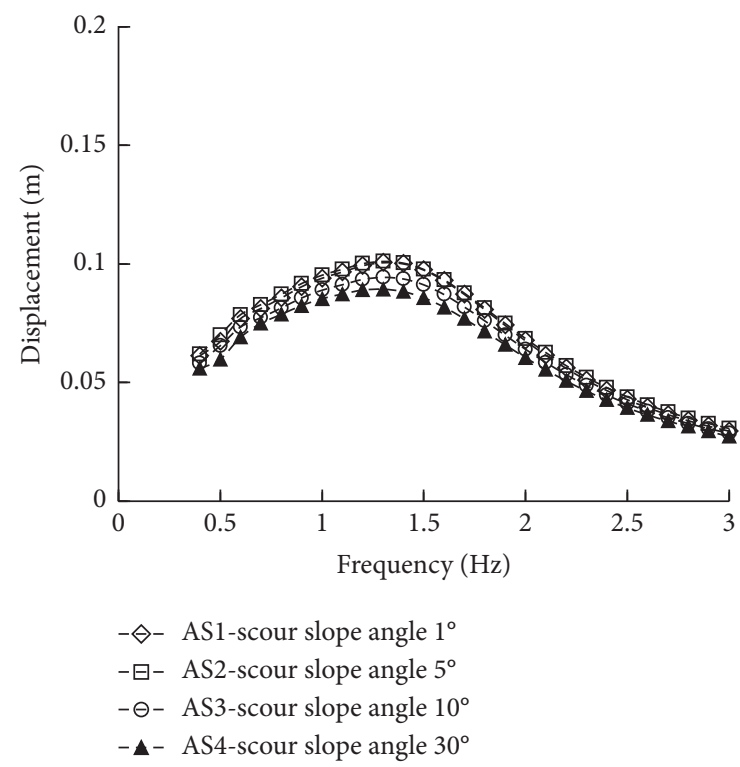

FIGURE 16: Effect of slope angle on the dynamic response of caisson foundation $\left(S_{d}=0.15 d\right)$. further through a three-dimensional model. However, given its simplicity, the proposed method can still obtain the dynamic response of the scoured caisson foundation from a qualitative perspective.

\section{Conclusions}

In this paper, the dynamic characteristics of the caisson foundation before and after scouring have been studied. A simplified method was developed to evaluate the effects of the scour-hole dimensions on the responses of the laterally loaded caisson in layered soils. The influence of three factors of the scour-hole dimension on the dynamic characteristics of the foundation is discussed. The following conclusions can be drawn:

(1) Scour depth is the most important factor influencing the dynamic displacement and resonant frequency of the laterally loaded caisson foundation, whereas the scour width does less and the slope angle does the least. An increase in scour depth significantly increases the lateral displacement and decreases resonant frequency of foundation.

(2) An increase in scour width and scour slope angle correlates with an increase in dynamic displacement of the caisson at first, and then the peak value of displacement remains constant with the increase in the scour width and scour slope angle. It can also be found that the effect of scour width could be ignored when the width was greater than or equal to $5 B$ and the effect of scour slope angle could be ignored when the scour slope angle was less than or equal to $5^{\circ}$.

(3) The overall trend of the result is roughly consistent with the change pattern when scour depth is at different values, and it is found that the degree of displacement increases more significantly when the sour depth is at a larger value.

\section{Appendix}

The stiffness and damping coefficient of the distributed horizontal and rocking springs of soil $k_{x i}, c_{x i}$ and $k_{r i}, c_{r i}$ can be given as [16]

$$
\begin{aligned}
k_{x i} & =\frac{1}{d}\left(K_{h h}-K_{h}\right) . \\
c_{x i} & =\frac{1}{d}\left(C_{h h}-C_{h}\right), \\
k_{r i} & =\frac{1}{d}\left(K_{r r}-K_{r}+\frac{1}{3} d^{2} K_{h}-\frac{1}{3} d^{2} K_{h h}\right), \\
c_{r i} & =\frac{1}{d}\left(C_{r r}-C_{r}+\frac{1}{3} d^{2} C_{h}-\frac{1}{3} d^{2} C_{h h}\right),
\end{aligned}
$$

where 


$$
\begin{aligned}
& K_{h h}=\frac{4 G B}{2-v} I_{t w}, \\
& C_{h h}=\frac{B}{2 V_{s}} \cdot K_{h h} \cdot c_{h c} \text {, } \\
& K_{h r}=K_{r h}=\frac{1}{3} d K_{h h}, \\
& C_{h r}=C_{r h}=\frac{1}{3} d C_{h h}, \\
& K_{r r}=k_{r c} \cdot \frac{G B^{3}}{3(1-v)} \Gamma_{w} \\
& C_{r r}=\frac{B}{2 V_{s}} \cdot \frac{G B^{3}}{3(1-v)} \Gamma_{w} \cdot c_{r c} \\
& I_{t w}=1+0.21\left(\frac{d}{B}\right)^{0.5}+1.43\left(\frac{d}{B}\right)^{0.8} \\
& +0.30\left(\frac{d}{B}\right)^{1.3} \\
& c_{h c}=\left(0.68+0.57 \sqrt{\frac{2 d}{B}}\right) \\
& \Gamma_{w}=1+2.25\left(\frac{d}{B}\right)^{0.6}+7.01\left(\frac{d}{B}\right)^{2.5} \\
& k_{r c}=1-\frac{\mu_{1}}{1+\left(\mu_{1}^{2} / \mu_{2}^{2}\right)}, \\
& c_{r c}=\frac{\mu_{1}}{\mu_{2}}\left(1-k_{r c}\right)+0.32 \frac{d}{B}, \\
& \mu_{1}=0.33+0.4\left(\frac{d}{B}\right)^{2} \\
& \mu_{2}=0.4+0.12\left(\frac{d}{B}\right)^{2} \text {, }
\end{aligned}
$$

where $G, v$, and $V_{\mathrm{s}}$ are the shear modulus, Poisson's ratio, and shear wave velocity of soil.

\section{Data Availability}

Data used to support the findings of this study are included within the manuscript.

\section{Conflicts of Interest}

The authors declare that there are no conflicts of interest regarding the publication of this paper.

\section{Acknowledgments}

This work was financially supported by the National Natural Science Foundation of China (Grant nos. 51808220 and 51822809), the Natural Science Foundation of Jiangxi Province (Grant nos. 20192BAB216036 and 20192ACBL21003), and the Shanghai Municipal Science and Technology Major Project (Grant no. 2017SHZDZX02).

\section{References}

[1] F. Liang, C. Wang, M. Huang, et al., "Scale effects on local scour configurations around caisson foundation and dynamic evolution," China Journal of Highway and Transport, vol. 29, no. 9, pp. 59-67, 2013, in Chinese.

[2] G. Dai, H. Dai, Y. Yang, et al., "Computation method and bearing characteristics of lateral bearing single pile foundation under scour condition," China Journal of Highway and Transport, vol. 31, no. 8, pp. 104-112, 2018, in Chinese.

[3] C. Chen, "Model experiment and study on local scour of large scale floating open caisson foundation," Highway, vol. 12, pp. 18-21, 2010, in Chinese.

[4] Z. Lu, Z. Gao, and C. Yang, "Experimental study on local scour during large caisson foundation construction," in Proceedings of the 14th China Ocean Engineering Symposium, Huhehaote, China, August 2009, pp. 260-267, in Chinese.

[5] W. Peng, J. Shen, X. Tang, et al., "Review, analysis, and insights on recent typical bridge accents," China Journal of Highway and Transport, vol. 32, no. 12, pp. 1139-1146, 2019, in Chinese.

[6] J. Liu, X. Chen, Z. Zhu, et al., "Investigation of scour effects on lateral behaviors of suction caisson," Marine Georesources and Geotechnology, vol. 37, no. 2, pp. 142-151, 2019.

[7] C. Zhang, X. Zhang, M. Huang, et al., "Responses of caissonpiles foundations to long-term cyclic lateral load and scouring," Soil Dynamics and Earthquake Engineering, vol. 119 , pp. $62-74,2019$.

[8] W. Tu, M. Huang, X. Gu, and H.-P. Chen, "Nonlinear dynamic behavior of laterally loaded composite caisson-piles foundation under scour conditions," Marine Georesources and Geotechnology, pp. 1-16, 2020.

[9] W. Tu, M. Huang, X. Gu, H.-P. Chen, and Z. Liu, "Experimental and analytical investigations on nonlinear dynamic response of caisson-pile foundations under horizontal excitation," Ocean Engineering, vol. 208, Article ID 107431, 2020.

[10] M. Zhao, X. Zhu, L. Cheng, and B. Teng, "Experimental study of local scour around subsea caissons in steady currents," Coastal Engineering, vol. 60, pp. 30-40, 2012.

[11] F. Liang, C. Wang, and X. Yu, "Widths, types, and configurations: influences on scour behaviors of bridge foundations in non-cohesive soils," Marine Georesources and Geotechnology, vol. 37, no. 5, pp. 578-588, 2019.

[12] F. Li, J. Han, and C. Lin, "Effect of scour on the behavior of laterally loaded single piles in marine clay," Marine Georesources and Geotechnology, vol. 31, no. 3, pp. 271-289, 2013.

[13] F. Liang, X. Liang, H. Zhang et al., "Seismic response from centrifuge model tests of a scoured bridge with a pile-group foundation," Journal of Bridge Engineering, vol. 25, no. 8, pp. 1-13, 2020.

[14] X. Yang, C. Zhang, M. Huang, and J. Yuan, "Lateral loading of a pile using strain wedge model and its application under scouring," Marine Georesources and Geotechnology, vol. 36, no. 3, pp. 340-350, 2018. 
[15] H. Zhang, S. Chen, and F. Liang, "Effects of scour-hole dimensions and soil stress history on the behavior of laterally loaded piles in soft clay under scour conditions," Computers and Geotechnics, vol. 84, pp. 198-209, 2017.

[16] M. Huang, W. Tu, and X. Gu, “Time domain nonlinear lateral response of dynamically loaded composite caisson-piles foundations in layered cohesive soils," Soil Dynamics and Earthquake Engineering, vol. 106, pp. 113-130, 2018.

[17] J. B. Kennedy, J. T. Laba, and M. A. Mossaad, "Reinforced earth retaining walls under strip load," Canadian Geotechnical Journal, vol. 17, no. 3, pp. 382-394, 1980.

[18] J. Yang and X. Q. Gu, "Shear stiffness of granular material at small strains: does it depend on grain size?" Géotechnique, vol. 63, no. 2, pp. 165-179, 2013.

[19] B. O. Hardin and V. P. Drnevich, "Shear modulus and damping in soils: design equations and curves," Journal of Soil Mechanics and Foundations Divison, vol. 98, no. 7, pp. 667692, 1972.

[20] T. Kagawa and L. M. Kraft, "Lateral load deflection relationships of piles subjected to dynamic loadings," Soils Foundation, vol. 20, no. 4, pp. 19-36, 1980.

[21] D. A. Varun, D. Assimaki, and G. Gazetas, "A simplified model for lateral response of large diameter caisson foundations-Linear elastic formulation," Soil Dynamics and Earthquake Engineering, vol. 29, no. 2, pp. 268-291, 2009.

[22] M. Huang, J. Yu, and C. Zhang, "P-y curves of laterally loaded piles in clay based on strain path approach," Chinese Journal of Geotechnical Engineering, vol. 37, no. 3, pp. 400-409, 2015, in Chinese. 